\title{
Towards a theory-driven research agenda in six sigma quality innovation: linking research opportunities with organization theory typology
}

\author{
Ram Narasimhan ${ }^{1 *}$ and Anand Nair ${ }^{2}$
}

\author{
* Correspondence: \\ narasimh@broad.msu.edu \\ ${ }^{1}$ College of Business, Michigan State \\ University, East Lansing, MI 48824, \\ USA \\ Full list of author information is \\ available at the end of the article
}

\begin{abstract}
Implementations of Six Sigma quality innovation (SSQI) have resulted in performance benefits for several leading firms. While SSQI has its roots in the foundations of Total Quality Management (TQM) and ISO 9000 certification, it presents a set of unique organizational practices and ideas that provide an opportunity for interesting and important investigations of relevance to operations and supply chain management. With a few notable exceptions, the academic literature in operations management has not given sufficient attention to various aspects of SSQI. In this paper, we identify some potential areas for future research and develop research questions pertaining to these areas. We call for theory-driven investigations by presenting a framework for linking SSQI research issues with appropriate theoretical perspectives. Using the unit of analysis and the various perspectives for managerial action as a basis, the typology presents six categories of organization theories. The typology provides a convenient basis for categorizing the research issues in SSQI based on their underlying theoretical rationale. We use the linkages between the research issues in SSQI and the theoretical perspectives to develop research propositions that could potentially aid and instigate theory-driven research studies in quality innovation.
\end{abstract}

Keywords: Quality management; Six Sigma quality improvement; Organization theory; Theory-building

\section{Background}

Six Sigma quality innovation (SSQI) ${ }^{\mathrm{a}}$ holds a lot of promise as firms continue to pursue quality-based innovation efforts. In contrast to radical innovation, SSQI seeks to exploit path dependency in incremental innovations that also improve the quality of a product or service. The origins of Six Sigma are marked by remarkable success gained by several leading organizations such as Motorola, ABB, and GE (cf. Harry and Schroeder 2000). SSQI is broader than six sigma in that its objectives are to not only improve quality but also the innovation content of products. SSQI leads to improved innovation output, competitiveness and profitability of firms.

Harry and Schroeder (2000) claim that companies who currently operate at three sigma level and who aggressively pursue Six Sigma implementation in their organizations can achieve a one sigma shift in improvement every year. According to the authors, these companies can achieve - (i) a 20 percent margin improvement, (ii) a 12 to 
18 percent increase in capacity, (iii) a 12 percent reduction in the number of employees, (iii) a 10 to 30 percent capital reduction, (iv) $\$ 230,000$ returns per project for each employee training in Six Sigma breakthrough strategy until the company reaches 4.7 sigma level. General Electric reduced its cost of quality from 20 percent to less than 10 percent in two years by raising its overall sigma level from four to five sigma. This resulted in an increase of $\$ 1$ billion in net income. GE's 1998 Annual Report highlights the financial impact of Six Sigma implementation (Harry and Schroeder 2000):

The potential performance benefits of SSQI are a compelling reason to investigate the various facets of the SSQI approach. Some major practitioner oriented outlets, such as Harvard Business Review and Sloan Management Review, have begun publishing articles on SSQI (see for example, Hammer 2002; Sodhi and Sodhi, 2005). Rigorous theory driven research in Six Sigma has also received heightened interest in recent years (see for example, Linderman et al. 2003; McAdam and Lafferty 2004; Zu et al. 2008; Nair et al. 2011; Easton and Rosenzweig 2012; Swink and Jacobs 2012), however, scholars are yet to embrace the full range of perspectives offered by organization theory. This paper seeks to promote research in SSQI by considering a larger set of organizational theories and focuses on the following questions:

- What are the aspects of the SSQI that still remain unaddressed in literature and present opportunities for further research investigations?

- What are the theoretical perspectives that could foster theory-driven research in SSQI?

We address these questions by using a typology presented in Pfeffer (1982) that provides a good basis for categorizing organizational theories. The categorization enables an investigation of linkages of various theoretical perspectives with potential areas of research in SSQI.

The rest of the paper is structured as follows. In the second section, we present ten key areas for future research in SSQI and highlight some research questions. Next, we highlight the need for theory-driven research in SSQI and present the organization theory typology that categorizes the various theoretical perspectives. In the fourth section, we present linkages of various theoretical perspectives to the potential research issues in the ten areas of SSQI. We develop research propositions that can be examined in future empirical studies. Finally, in the fifth section we summarize the paper and conclude.

\section{Research opportunities in SSQI}

In this section we present ten potential areas for future research in SSQI. The key issues in these areas are highlighted and the potential research questions are identified.

\section{SSQI \& total quality management (TQM): distinction \& integration}

Systematic study of SSQI must begin with an understanding of the key difference between the principles of SSQI and TQM. This will enable closer integration of the TQM literature with future research endeavors in SSQI.

According to Harry and Schroeder (2000) the difference between TQM and SSQI is one of focus. TQM programs focus on improvements in individual operations within unrelated processes. Thus, with many quality programs, it takes several years before all 
the operations within a given process are improved. In contrast, in Six Sigma the focus is on improving all operations within a process leading to results more rapidly and effectively.

Pande et al. (2000) delineate the key differences between Six Sigma and TQM approaches in terms of the following aspects: integration with the overall business strategy, engagement of top management, clarity of message, clarity of goal, adaptation and rigor of the underlying tool set, cross-functional integration, approach to change management, formalization of training procedures \& scope of impact of the underlying practices. A detailed examination of these aspects can aid our understanding of the differences between the two approaches and how best to utilize them in practice.

\section{SSQI readiness level}

According to Pyzdek (2001), company quality culture - the opinions, beliefs, traditions, and practices concerning quality (Juran and Gryna 1988, 1993) - plays a critical role in determining an organization's readiness to implement SSQI projects. Implementing SSQI projects requires that the organization is ready for change. The decision to change should be guided by an assessment of the outlook and future path of the business, evaluation of current performance, and a thorough review of systems and capacity for change. Pande et al. (2000) suggest that SSQI readiness can be assessed by examining if the change is a critical business need based on profit goals, cultural and competitive needs. SSQI readiness is dependent on top management commitment to quality innovation and a clear understanding of the potential business impact from it. Firms undertake SSQI projects either reactively or proactively. For example, SSQI was a reactive move by Motorola, due to the quality problems it faced in late 1970s (Harry and Schroeder, 2000). A firm's SSQI readiness must be evaluated by considering the specific approach (proactive or reactive) taken for quality innovation.

\section{Top management support}

Top management support has been recognized as important for successful quality improvement implementation (for example, Powell 1995; Adam et al. 1997; Samson and Terziovski 1999). Leadership fosters change in an organization through continuous improvement and open communication (Kaynak 2003) and this potentially explains the improvement in financial performance, customer service and product quality. Studies have also observed that leadership improves performance indirectly through its influence on other quality management practices (Anderson et al. 1995; Flynn et al. 1995; Ahire and O'Shaughnessy 1998; Wilson and Collier 2000). These assertions regarding top management's role in quality management initiatives also hold for SSQI.

Top management commitment and resource allocation are critical for successful SSQI implementation. General Electric is a case in point in which the top management under CEO Jack Welch committed approximately \$ 200 million in 1996 to training. Subsequently, in 1997, GE invested an additional \$250 million in training. The result was that in 1997 alone, Six Sigma added \$300 million to GE's operating income. In 1998 , the $\$ 500$ million dedicated to the initiative were offset by over three quarters of a billion dollars in savings and an approximate savings of \$1.5 billion in 1999 (Harry and Schroeder 2000). The evidence provides support for the importance of top management support for SSQI. Research studies can examine and validate the role of top 
management by considering contingent factors and other critical issues pertaining to the link between top management support and SSQI implementation success.

\section{Choice of appropriate metrics}

Melnyk et al. (2004) argue that metrics establish an important link between strategy, execution, and ultimate value creation. They assert that research on metrics has not kept pace with their increasing importance and emphasize that proactively designing and managing metrics is needed to be successful in today's competitive environment. Metrics play an important role in SSQI.

For appropriately choosing SSQI metrics, a company must be aware of its current performance. It is important to choose metrics that are measurable, unambiguous and are crucial to the success of an organization (Nair et al. 2011). An improperly chosen metric can be detrimental for successful implementation of SSQI. For example, it can lead to suboptimal behavior on the part of employees (Pyzdek 2001), demotivate employees, and can deter organizational constituents from adopting future SSQI initiatives. Rose (1995) asserts that good metrics are either customer-centered with a focus on indicators that provide value to customers, or they are associated with internal work processes.

Firms must consider the factors such as context, constraint, and boundary when developing appropriate metrics (Nair et al. 2011). It is important to understand how the measures (i.e., data items) and their associated performance will be assessed. There must be consistency and full understanding regarding how organizational performance is influenced by the chosen measures. A validated approach, specifying how the data will be collected and used in the organization is essential.

Harry and Schroeder (2000) argue that the traditional metrics focus on the end results and on the final product or service, for example, product margins, scrap, and rework. In the SSQI approach, it is important to focus on the processes that generate the problem. A process-based view is thus a hallmark of organizations who have successfully implemented SSQI projects. For example, if an organization considers customer satisfaction as important, it is critical to define the customers and to understand what they value the most. The organization should measure and report the factors, also called "critical-to-quality" characteristics or CTQs that affect customer satisfaction.

In SSQI, process metrics - such as throughput yield, rolled throughput yield, and normalized yield - are based on the defects produced and thus expose hidden factories that are left undetected in the traditional yield metrics that focus on the number of units produced. These SSQI process metrics are "defect sensitive" instead of being "unit sensitive" and have high statistical correlation to labor, costs, cycle time, and work in process (Harry and Schroeder 2000). A systematic study that compares the traditional metrics with the SSQI process metrics is needed.

Creating dynamic metrics is essential for SSQI and further research can contribute to a better understanding of the design and evolution of dynamic metric systems. Finally, a study of metrics must consider the unit of analysis. While the metrics at each level of an organization are complementary, they need different perspective for effective SSQI initiatives. At the business level, SSQI is used to improve market share, increase profitability, and ensure the corporation's long-term viability. At the operations level, SSQI seeks to improve yield, eliminate hidden factories, and reduce labor 
and material costs. At the process level, SSQI is used to reduce defects and improve process capability in ways that impact business and operational goals (Harry and Schroeder 2000).

\section{Project selection}

Organizations should select SSQI projects that are promising and that could result in improved profit performance (Nair et al. 2011). It is essential to consider the impact decrease in product cost, improved delivery schedules, and more product features that are easily discerned by the customer - as well as the feasibility - in terms of project scope, cost, and top management support - when selecting SSQI projects. According to Pande et al. (2000), clear objectives, scope and timeframe, are the key factors in SSQI project selection. An in-depth investigation of the trade-offs between impact and feasibility dimensions and their relative importance vis-à-vis organizational contingencies is a fruitful area of future research.

\section{Project management}

A distinguishing feature of SSQI is that it is undertaken as a formal project and as such project management considerations apply. SSQI project teams are comprised of "the Sponsor/Champion," "the Master Black Belt," "the Black Belt," "the Green Belt or Team Leader," and "Improvement team". The team structure is context dependent. The various contexts that influence team structure include: types of processes, the black belt role in an organization, the objectives of the SSQI initiative, and the role of a consultant or advisor for SSQI project implementation.

SSQI project implementation allows a firm to undertake process improvement and innovation by using DFSS. The implementation cycle, denoted by DMAIC (Define, Measure, Analyze, Improve, and Control), provides a feedback mechanism to ensure a systematic approach to quality innovation. Harry and Schroeder (2000) added two additional phases of "standardize" and "integrate" to the DMAIC cycle and suggest that the eight phases can be aggregated into four categories: Identification (Recognize and Define); Characterization (Measure and Analyze); Optimization (Improve and Control); Institutionalization (Standardize and Integrate). A rigorous characterization of these categories in terms of constituent elements, methodologies, relative importance and contingencies is a potential area for future research.

Understanding aspects of project management such as project organizational structure, project charter, project risk, conflict resolution and, control and coordination would be helpful in developing standard protocols for successful implementation of SSQI projects.

\section{Context dependence}

Recent research in quality management has recognized the role of context and moderators of the relationship between quality management practices and performance. For example, Douglas and Judge (2001) found strong support for the moderating influence of organizational structure on implementation effectiveness. Specifically, two measures of organizational structure - control and exploration - were found to offer independent and interdependent influences on the financial performance of firms implementing quality management programs. Very few survey-based empirical studies have examined the role of contextual variables in assessing the effectiveness of quality management practices on performance (Benson et al. 1991; Sousa and Voss 2001). 
Research in SSQI needs to incorporate context and moderating variables in its initial stages of theory building (Nair et al. 2011; Swink and Jacobs 2012).

\section{Process design/redesign}

Process design/redesign for SSQI, commonly referred to as Design for Six Sigma (DFSS), is an approach that doesn't have a precedent in the earlier quality management movement. TQM and other quality initiatives emphasized incremental process improvement and there was no explicit provision for radical and innovative changes in processes.

SSQI approach involves both incremental and radical changes in processes to achieve the required quality improvement. Further research is needed to have a better understanding of DFSS.

\section{Ongoing improvement}

Sustaining SSQI requires that the changes and new methods be documented and the documentation be simple, brief and handy. Pande et al. (2000) suggest three types of measures - maintenance-oriented, situational and improvement-focused.

The institutionalization phase that is comprised of "standardize" and "integrate" stages is particularly significant for continuous improvement. In the standardize phase, the various SSQI projects undertaken by an organization are linked and best practices are identified so that these practices can be standardized within and across businesses. The integrate phase, improves the processes by using the best practices as a basis. Further research is needed to explore the various issues pertaining to ongoing improvement.

\section{Increasing/diminishing returns}

It is reasonable to speculate that SSQI benefits cannot continue indefinitely. Harry and Schroeder (2000) suggest that within a range of sigma level a firm achieves increasing returns from SSQI implementation but subsequently the investments result in diminishing returns. This relationship is likely influenced by sigma level, process complexity and quality improvement. The investigation of this relationship can be a topic of future research.

The key areas for potential research in SSQI and the associated research questions are presented in Table 1.

\section{Need for Six sigma research rooted in theory}

The preceding section used practitioner-oriented outlets for categorizing the potential research areas and presented associated research issues. Efforts towards theory-building in SSQI must be undertaken to gain deeper insights. Linderman et al. (2003: pp. 193) highlight that SSQI "lacks a theoretical underpinning and a basis of research other than 'best practice' studies" and use the goal theoretic perspective to develop an understanding of SSQI. They assert that goal theory can help in understanding quality management in general, and SSQI in particular. Similar to SSQI, goal theory emphasizes goals that are clearly specified and measured rather than the fuzzy and "do-best" goals. Goal theory relates to goal setting and goal achievement and presents a good basis for SSQI.

In this paper, we present additional theoretical perspectives for further research in SSQI. To guide our understanding of the linkages between the theoretical perspectives and the 
Table 1 Potential research questions

\begin{tabular}{|c|c|}
\hline Issues & SSQI \& TQM \\
\hline \multirow[t]{2}{*}{ Integration } & - Which factors in SSQI enable its integration with the business strategy? \\
\hline & - How can SSQI be integrated with administrative or service processes? \\
\hline Leadership & $\begin{array}{l}\text { - Is the nature of top management's support for Six Sigma initiatives } \\
\text { fundamentally different from their support for TQM initiatives? What are } \\
\text { the reasons for the difference? }\end{array}$ \\
\hline \multirow[t]{2}{*}{ Fuzziness } & - What are the factors that contribute to the fuzziness of TQM? \\
\hline & $\begin{array}{l}\text { - Integration of practices and philosophies professed in TQM literature with } \\
\text { Six Sigma. }\end{array}$ \\
\hline Goal-orientation & $\begin{array}{l}\text { - What are the feedback mechanisms to dynamically adapt Six Sigma goals } \\
\text { with changing conditions? }\end{array}$ \\
\hline \multirow[t]{2}{*}{ Use of tools } & - Impact of "quality purism" on TQM success. \\
\hline & - Implications of technical zealotry in Six Sigma implementation. \\
\hline Cross-functional orientation & $\begin{array}{l}\text { - Cross-functional collaboration in Six Sigma vs. departmentalized approach } \\
\text { in TQM. }\end{array}$ \\
\hline "OR" vs. "AND" orientation & $\begin{array}{l}\text { - What are the unique governance mechanisms in Six Sigma that enable } \\
\text { firms to undertake both small improvements (as in TQM) and major } \\
\text { process redesigns (as in re-engineering)? }\end{array}$ \\
\hline Training & - What is the significance of context in Six Sigma training? \\
\hline Focus & - What is the evolutionary nature of focus of Six Sigma project goals? \\
\hline Issues & SSQI Readiness Level \\
\hline \multirow[t]{2}{*}{ Strategic intent } & $\begin{array}{l}\text { - Six Sigma implementation as a proactive means for improving competitive } \\
\text { position vs. Six Sigma as a reactive strategy to stave off future disaster } \\
\text { (e.g. the case of Motorola). }\end{array}$ \\
\hline & - Six Sigma readiness indicators for a proactive and a reactive approach. \\
\hline \multirow[t]{2}{*}{$\begin{array}{l}\text { Relationship with } \\
\text { implementation success }\end{array}$} & $\begin{array}{l}\text { - What is the relationship between Six Sigma readiness level and Six Sigma } \\
\text { implementation success? }\end{array}$ \\
\hline & $\begin{array}{l}\text { - What is the relationship between number of Six Sigma projects implemented } \\
\text { and Six Sigma readiness level of a firm? }\end{array}$ \\
\hline Issues & Top Management Support \\
\hline \multirow[t]{3}{*}{ Role of top management } & $\begin{array}{l}\text { - Top management's role in supporting: (i) the development of a strong } \\
\text { rationale for Six Sigma; (ii) for setting clear objectives and, (iii) for continued } \\
\text { Six Sigma initiatives. }\end{array}$ \\
\hline & - Top management's role in instituting "hard" measures to gauge the impact \\
\hline & - Top management's role in ensuring accountability at all levels. \\
\hline \multirow{2}{*}{$\begin{array}{l}\text { Rewards, penalties \& } \\
\text { motivation protocols }\end{array}$} & - Rewards and penalties for successful Six Sigma implementation. \\
\hline & $\begin{array}{l}\text { - Mechanisms for communicating favorable as well as unfavorable results and } \\
\text { for maintaining the momentum towards Six Sigma quality. }\end{array}$ \\
\hline Issues & Choice of Appropriate Metrics \\
\hline \multirow[t]{6}{*}{ Integration \& Aggregation } & - Integration of Six Sigma measures with observed data. \\
\hline & - Integration of continuous and discrete measures of performance. \\
\hline & $\begin{array}{l}\text { - Mechanisms for streamlining the process for measurement for effective and } \\
\text { efficient Six Sigma implementation. }\end{array}$ \\
\hline & - Aggregation of metrics at different organizational levels. \\
\hline & $\begin{array}{l}\text { - Integration of Six Sigma project metrics with the real or perceived reward } \\
\text { structure. }\end{array}$ \\
\hline & - Tradeoff between richness and complexity of Six Sigma metrics. \\
\hline \multirow[t]{3}{*}{ Theoretical issues } & - Links between process-based view of SSQI and the resource-based view. \\
\hline & - Dynamic evolution of Six Sigma process measures of performance. \\
\hline & - What is the "metrics typology" of SSQI? \\
\hline Strategic \& Operational Intent & - Fit between Six Sigma metrics system and the strategic intent of a firm. \\
\hline
\end{tabular}


Table 1 Potential research questions (Continued)

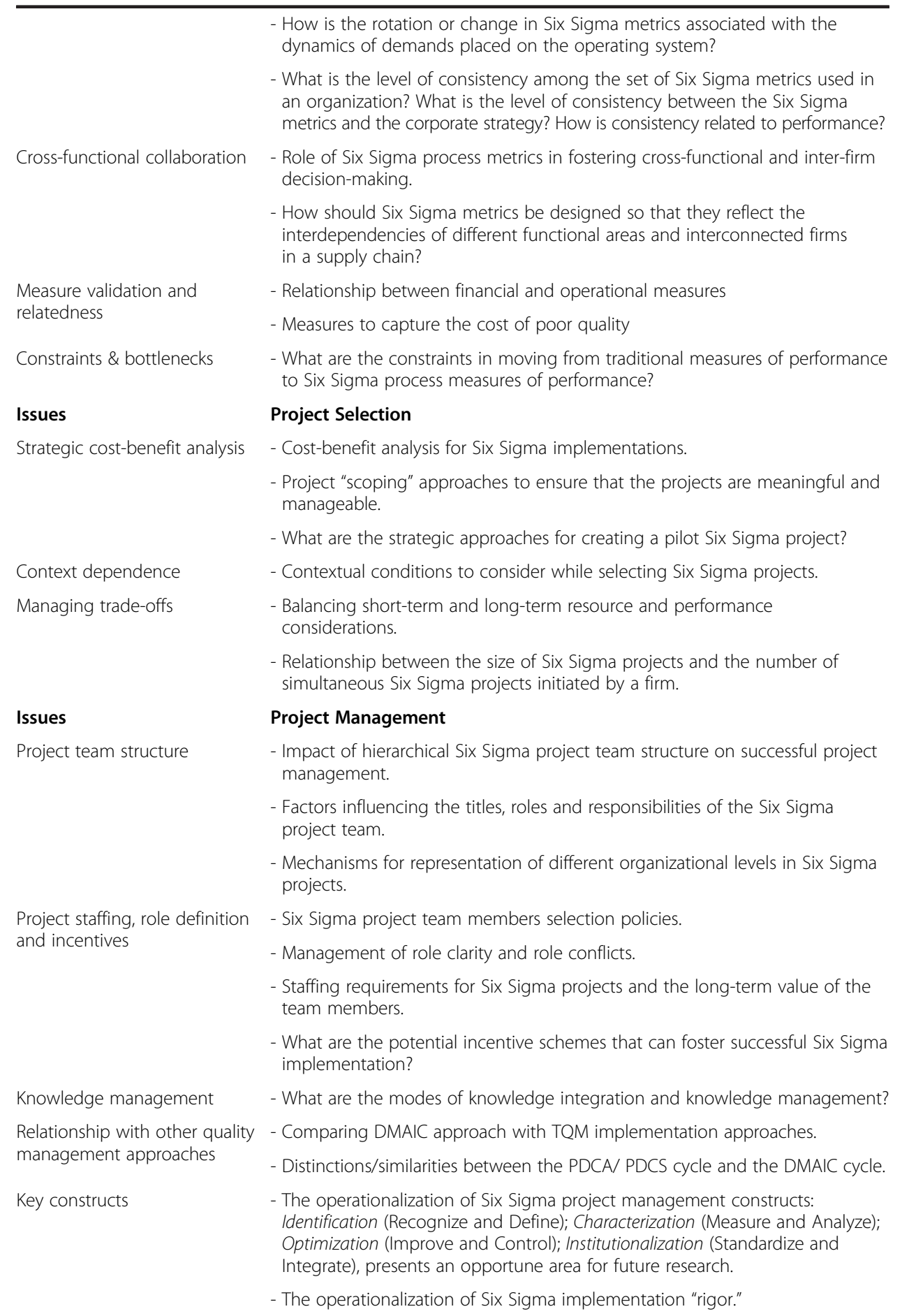

\section{Issues}

\section{Context Dependence}

Role of moderating variables in Six Sigma success

- Moderating variables influencing the relationship between implementation and success of SSQI initiatives.

- Moderating role of organizational context on the relationship between Six Sigma implementation "rigor" and Six Sigma implementation success.

Issues

\section{Process Design/ Redesign}

Conceptualizing DFSS 
Table 1 Potential research questions (Continued)

\begin{tabular}{ll}
\hline & - Milestones for evaluating the success of Six Sigma Process Design. \\
$\begin{array}{l}\text { Comparison with } \\
\text { Re-engineering }\end{array}$ & - Comparing Design for Six Sigma (DFSS) and the Business Process \\
Issues & Re-engineering (BPR) approach. \\
Institutionalization & Ongoing Improvement \\
& - Institutional norms enabling ongoing improvement. \\
& - Constraints in institutionalizing continuous improvement. \\
& - Influence of centralization/decentralization on the role and responsibilities \\
& of Process Owner responsible for continuous improvement. \\
Hierarchy of measures and & - Relationship between maintenance-oriented, situational and improvement \\
inter-relationship & focused measures for ongoing improvement. \\
Issues & Increasing/ Diminishing Returns \\
Increasing returns and & - Theoretical explanation for the relationship between returns from Six Sigma \\
trade-offs & implementation and sigma level of a firm. \\
Contingent factors & - Timing consideration for DFSS implementation. \\
& - Relationship between product capability and Six Sigma/DFSS Relationship \\
& between process complexity and Six Sigma/DFSS
\end{tabular}

potential research issues in SSQI, we utilize the organization theory typology suggested by Pfeffer (1982). In the typology, organizational theories are classified based on their perspectives on action and their level of analysis. Three perspectives on action are suggested. These are:

- Purposive, intentional, goal-directed, rational

- Externally constrained and controlled

- Emergent, Almost-Random, Dependent on Process and Social Construction

The level of analysis can be categorized into two types:

- Individuals, Coalitions or Subunits

- Total organization

Based on the three perspectives on action and the two levels of analysis, organization theories can be categorized into six types as shown in Table 2 .

Next, we briefly discuss the characteristics of the six categories and highlight the key arguments pertaining to each theoretical perspective.

\section{Category I}

In these theories the focus is on individual-level concepts such as preferences, goals, values, or needs and social action is often implicitly assumed to be resulting from the aggregation of individual-level behavior or behavior-determining processes. Rational utilitymaximization is the core idea. These theories presume a preexisting purpose or intent and rely on cognitive information-processing capability of an individual. Context does not play an important role in these theories. Specific theoretical perspectives in this category are:

Expectancy theory argues that people undertake actions according to the probability that these actions will lead to some instrumentally valued outcome (e.g. Vroom, 1964). 
Table 2 Pfeffer's typology of theoretical perspectives in organization theory

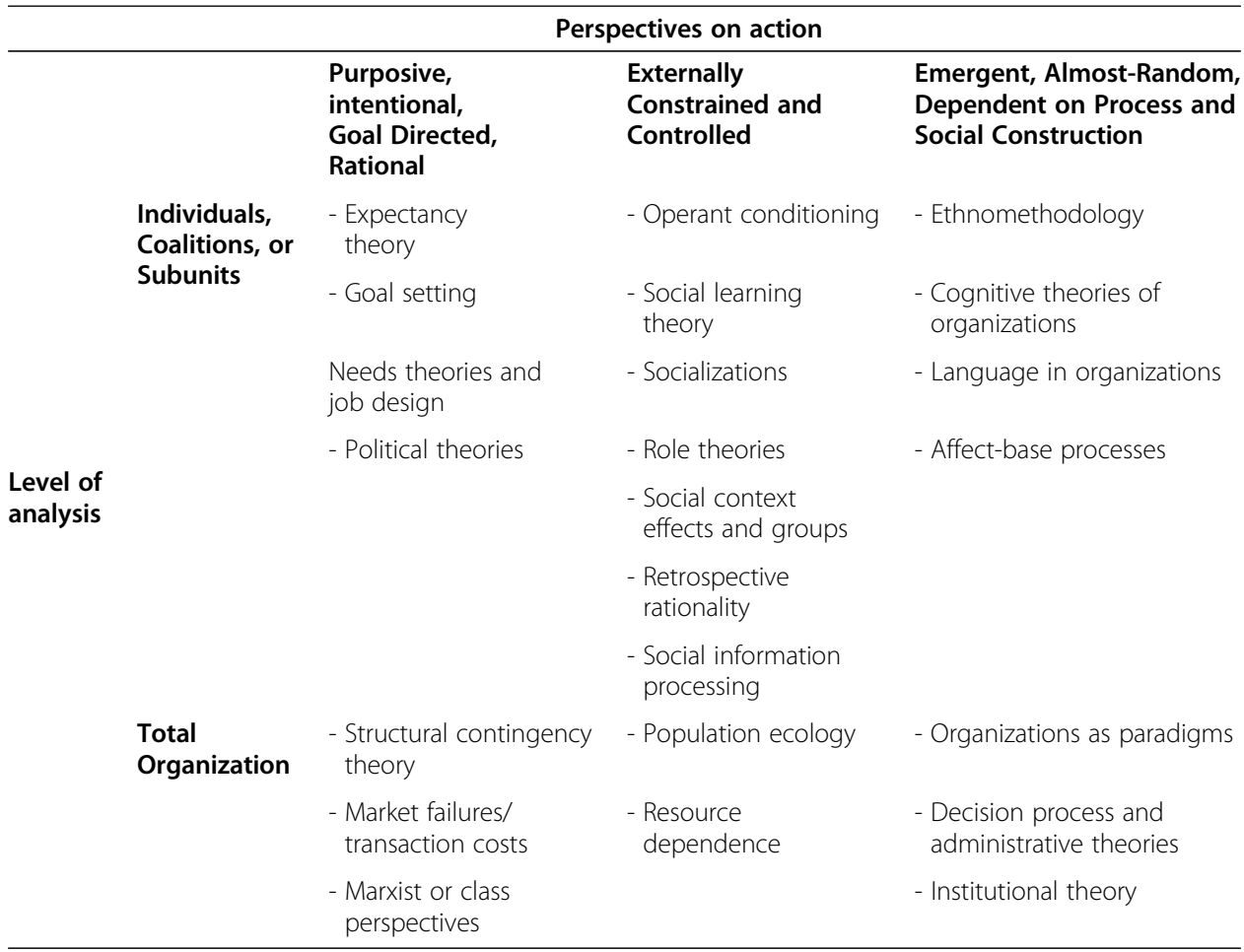

Goal Setting suggests a rational, consciously chosen, motivated individual behavior emphasizing cognitive processes to achieve their goals (e.g. Locke, 1968).

Needs theory $\&$ job design argues that people act purposefully to fulfill their needs or to overcome need deficiencies (e.g. Alderfer 1972; Maslow 1943).

Political theories assert that individual action is motivated to achieve some desired outcome such as more resources, promotion, or additional power (e.g. Pfeffer 1981).

\section{Category II}

The basic premise of these theories is that individuals are adaptive to their environments and therefore to understand behavior it is both necessary and largely sufficient to consider only the characteristics and constraints of the environment in which the individuals act.

Operant conditioning perspective argues that behavior is a function of its consequences. Positive reinforcement increases the frequency of a behavior in the future, whereas, negative reinforcement decreases the frequency of future occurrences of the behavior. (e.g. Skinner 1953)

Social learning theory considers the role of cognition in the learning process and admits learning through a variety of means such as vicarious learning, in which behavior and consequences to another individual serve as a learning experience, and learning from explicit emulation (e.g. Bandura 1977).

Socialization emphasizes the understanding of the organization's culture, way of doing things, and decision-making style that is internalized in the individual (e.g. Van Maanen 1976). 
Role theory argues that organizations are systems of mutual social constraint in which the activities of any given role occupant are determined by the demands and expectations of others in his or her role set (e.g. Kahn et al. 1964)

Social context effects $\mathcal{E}$ groups perspective emphasize the effects of the attitudes and behaviors of others in the individual's environment on his or her own attitudes and behavior (e.g. Blau 1960; Blalock 1967).

Retrospective rationality theories, unlike theories that assert that behavior is prospectively rational and consciously chosen to obtain some goal, suggest that behavior is largely under some external control and behavior is rationalized after the fact (e.g. Aronson 1972).

Social information processing theories suggest that social context affects the perceptions of the work environment, attitudes, and need statements; perceptions and attitudes are linked; and an individual's own past behaviors, which are partly socially mediated, affect self-perceptions of attitude (e.g. Salancik and Pfeffer 1978).

\section{Category III}

These theories recognize individuals as the creator of meaning and their focus has been on the subjective nature of reality and on the constraining effects of social definitions of reality on behavior. The theoretical perspectives are:

Ethnomethodological approach is characterized by its relative emphasis on a situation-specific frame of reference and its emphasis on cognitive sense making (e.g. Gephart 1978).

Cognitive theories of organizations consider organizations as bodies of thought or causal schemata which are characterized by two dimensions - the differentiation \& complexity and the specific relationships embodied in the causal structure (e.g. Goodman 1968).

Language in organization perspective argues that language is important in understanding organizations and how they are managed because language is one of the key tools of social influence, and organizations are contexts in which social influence is exercised (e.g. Pondy 1978).

Affect-based processes assert that it is the affect or emotion that maintains the repetitiveness of behavior and maintain the interlocked cycles of interaction (e.g. Collins 1981).

\section{Category IV}

These theories presume rational and conscious action and address large-scale organizations as a whole rather than as environments in which individuals work, and are influenced by power, status and fulfillment of various needs and goals. The main points underlying the theoretical perspectives in this category are:

Structural contingency theory argues that the design of the organization depends on various contextual factors. The motivational assumptions are efficiency and strategic choice and the dependent variables typically relate to the form and structural dimensions (e.g. Galbraith 1973).

Market failures approach also referred to as the "transaction cost approach" emphasizes the role of transaction costs which could arise due to a number of 
conditions such as, small numbers or noncompetitive markets; opportunism; environmental uncertainty; and bounded rationality. The motivational assumption is efficiency and the dependent variables include boundaries and integration, form and organization of employment relations (e.g. Williamson 1975).

Marxist analysis of organizations focuses on the premise of conscious, rational, strategic action taken on the part of the capitalist class and organizations, controlled by that class. The motivational assumptions are power, accumulation, intergenerational transmission and the dependent variables include organization of employment relations, accumulation and allocation, patterns of association and the choice of technology (e.g. Heydebrand 1977).

\section{Category V}

Theories in this category address the issue of how, or if, organization-level rational choice or decision making gets produced. The two variants of this perspective: population ecology and resource dependence, differ in terms of behaviorism and social information processing seen at the individual level of analysis. Population ecology focuses attention on birth and death processes impacted by environmental conditions and the resource dependence theory focuses on internal adaptations and the politics that occur inside organizations. Theoretical perspectives in this category are presented below:

Population ecology theory argues that change in population of organizations occurs, in part, because of the operation of selection processes working on those organizations (e.g. Hannan and Freeman, 1977).

Resource dependence theory argues that organizations are externally constrained and therefore organizations seek to manage or strategically adapt to their environment. According to the theory it is important to pay greater attention to internal organizational political decision-making processes (e.g. Pfeffer and Salancik 1978; Aldrich and Pfeffer 1976).

\section{Category VI}

Organizations are conceived as paradigms and processes, and the explanation and prediction of behavior proceed by incorporating structural and contextual effects, while retaining some of the developmental perspective and the theme of social construction of reality. Specific theoretical perspectives in this category are:

Organizations as paradigms perspective conceptualizes organization in terms of the concept of paradigms, which refers to the shared understanding and beliefs about cause-effect relations and standards of practice and behavior (e.g. Brown 1978). Decision process theories and administrative rationality perspective argue that organizations develop performance programs, standard operating procedures, and rules of thumb, to make decisions; hence, it is necessary and largely sufficient to understand these performance programs or procedures (e.g. March and Olsen 1976). Institutionalization theory argues that the process of institutionalization is the main reason for practices or procedures to be continued and transmitted without question and for meanings to be shared without thought or evaluation. The theory on one end imparts permanence to an organization that extends beyond the requirements of 
the task at hand and on the other end addresses the processes by which social processes, obligations, or actualities come to take on a rule like status in social thought and action (e.g. Meyer and Rowan 1977).

\section{Theoretical linkages}

In this section, we revisit the ten broad areas of Six Sigma research and discuss the linkages with the various theoretical perspectives. By linking the potential research areas with the theoretical perspectives, we present directions for theory development SSQI.

\section{SSQI and TQM}

Studies are needed to establish that higher performance benefits can be had from SSQI compared to TQM. To examine this, a testable proposition could be stated as follows:

P1: Firms adopting the SSQI approach attain higher performance than those who adopt the TQM approach.

Multiple dimensions of performance can be examined in terms of financial performance, operational performance, product quality and customer service. The integration of SSQI with overall business strategy and with the administrative and service processes calls for theoretical perspectives in which the analysis is at the organization level. The resulting structural and strategic integration may be based on set goals, external constraints or may be emergent. Integration issues that are based on organizational goals can be explained by structural contingency theory. Specifically, structural contingency theory can be invoked to understand how managerial knowledge, operations strategy, time lag of the effectiveness of SSQI programs, manufacturing systems, product complexity, breadth of product line and frequency of product changes affect the integration of SSQI practices with business strategy and with administrative and service processes (Maani 1989; Benson et al. 1991; Kekre et al. 1995; Powell 1995; Ahire et al. 1996; Sousa and Voss 2001). The following proposition provides a basis to investigate the integration between SSQI and business strategy:

P2: The integration of SSQI approach with business strategy is influenced by internal contextual variables.

Integration issues can also be explained by considering the theoretical perspectives at organizational level that explain organizational behavior in terms of external constraints. Specifically, using the argument in resource dependence theory that organizations are externally constrained and adapt to environmental constraints, we can examine how the integration of TQM and SSQI approaches with the business strategy is influenced by contextual variables. We present the following proposition for further investigation:

P3: The integration of both SSQI and TQM approaches with business strategy is influenced by external contextual variables. 
Several external contextual variables can be investigated such as industry (Maani 1989; Powell 1995), country and cultural issues (Madu et al. 1995), external competitive requirements, and customer expectations regarding quality (Benson et al. 1991).

Finally, integration is also an emergent phenomenon in organizations. Thus, theoretical perspectives that explain the emergent behavior in an organizational level can be used to understand how SSQI (and TQM) approach is integrated with the operational and strategic intent of a firm. We can use the theoretical perspectives of organizations as paradigms, decision process theories and administrative rationality, and institutionalization theory to understand the emergent behavior. Organizations tend to develop shared norms regarding the cause-effect relationship between SSQI approach and performance, which either fosters or inhibits the integration of practices with business strategy and operational processes. We propose:

\section{P4: Organizational norms enable the integration of both the SSQI and the TQM approach with business strategy.}

Leadership plays an important role in TQM and SSQI programs. However, Pande et al. (2000) assert that the role, responsibilities and motivation level of top management differ in TQM and SSQI approach. Top management takes an active role in SSQI due to the clarity of goals. The impact of clarity of goals on top management commitment in the two approaches can be examined by using subunit level theoretical perspectives, such as goal setting (for example, Linderman et al. 2003) and expectancy theory. We present the following proposition:

\section{P5: Top management support for the implementation of SSQI projects is moderated by} goal clarity.

It is often argued that TQM has tended to adopt "quality purism", by relying on sophisticated quality tools. Researchers have concluded that rational comprehensive quality data analysis and information processing is of limited use or even counterproductive under conditions in which multiple problem definitions are possible, goals are ambiguous, or uncertainty is great (March and Olsen 1976; Daft and Lengel 1986; Daft et al. 1988; Lord and Maher 1990). To account for these conditions, structural contingency theory provides a suitable theoretical framework. Theories in category VI of the typology, i.e. organizations as paradigms, decision processes and administrative theories, and institutional theory, present the basis to understand how technical zealotry in quality management gets deeply rooted in organizational routines. We propose:

P6: Goal ambiguity moderates the relationship between quality data analysis and performance in both SSQI and TQM.

P7: Environmental uncertainty moderates the relationship between quality data analysis and performance in both SSQI and TQM.

The difference between the TQM and the SSQI approaches can be examined in terms of the level of cross-functional orientation. The structured approach of SSQI with representation from various functions at different levels presents a context that is conducive 
to cross-functional integration. Individual/ subunit level theories rooted in utility maximization and rational choice, such as goal setting, needs theory and job design, political theories; constraint and control oriented theories, such as social learning theory, role theories, social context effects and groups, and social information processing present foundations for understanding the cross-functional orientation in TQM and SSQI. At the total organization level, theories such as resource dependence theory, which emphasizes the inter-departmental dependence and power issues, and the theories of emergence, such as organizations as paradigms, decision process and administrative theories, and institutional theory provide the framework to investigate the issues of cross-functional collaboration. The following propositions are presented:

P8: SSQI is characterized by higher level of cross-functional collaboration than TQM.

P9: Cross-functional collaboration in SSQI is positively associated with goal congruence across functions.

SSQI is a process-based approach in which quality improvement in all operations within a process is accomplished, whereas, TQM focuses on improving all processes within an operation (Harry and Schroeder 2000). Moreover, Six Sigma tries to accomplish both incremental as well as radical process improvements, whereas the major thrust in TQM programs has been on incremental quality improvements. These issues can be theoretically examined by relying on goal setting and expectancy theories.

We present the following propositions:

P10: SSQI is positively associated with both incremental AND radical process improvements.

P11: TQM is positively associated with incremental process improvement but NOT with radical process improvements.

P12: The association between training and quality improvement in the SSQI approach is higher than their association in the TQM approach.

\section{SSQI readiness level}

Strategic intent of a firm plays a determining role in the SSQI readiness level. Expectancy theory, goal setting theory, structural contingency theory, transaction cost theory, decision processes and administrative theories provide the theoretical frameworks to examine the impact of strategic intent on SSQI readiness of a firm. Organizational culture is another determinant of the SSQI readiness level. Individual/ subunit level theories, such as political theories, social context effects and groups, cognitive theories of organizations, organizations as paradigms and institutional theory provide the basis for investigating organization culture issues. The following are testable propositions:

P13: Strategic intent of a firm is positively associated with the SSQI readiness level. P14: Organization culture is positively associated with the SSQI readiness level.

\section{Top management support}

Management leadership is important for the success of SSQI initiatives. Top management sets goals and expectations, initiates quality-oriented organizational norms, and 
appropriately manages the issue of job design and roles of people responsible for SSQI. These aspects of management leadership in SSQI initiatives can be examined by using the theoretical foundations of expectancy theory, goal setting, needs theory and job design, role theories, social information processing, language in organizations, decision processes and administrative theories and institutional theory. Top management is also responsible for setting appropriate reward structure to ensure that the employees are motivated to pursue SSQI. Theoretical perspectives such as operant conditioning, population ecology, decision processes and administrative theories and institutional theory can be invoked to gain further insight into the roles and responsibilities of top management and attendant organizational benefits. Research studies in TQM have observed that management leadership improves performance indirectly through its influence on other quality management practices (Anderson et al. 1995; Flynn et al. 1995; Ahire and O'Shaughnessy 1998; Wilson and Collier 2000). Structural contingency theory provides the theoretical lens for further investigation of the indirect effects of top management support in the SSQI approach.

P15: Top management support is positively associated with the performance benefits from SSQI approach.

\section{Metrics}

Measurement is a critical aspect of SSQI approach. Goal setting provides the foundation for several issues pertaining to SSQI metrics (e.g. Linderman et al. 2003). Future research can adopt expectancy theory and needs theory to understand how the various types of SSQI measures can be aggregated across different levels of an organization. The evolving nature of SSQI measures can be examined by resorting to the theoretical perspectives of organizational level emergence (category VI). Future studies can use structural contingency theory perspective to examine the fit between SSQI metrics and the strategic intent of a firm. SSQI metrics play an important role in cross-functional collaboration of a firm. The relationship between SSQI metrics and cross-functional collaboration can be examined by using theoretical perspectives such as, expectancy theory, goal setting, needs theory, role theories, social context effects, social information processing theory, social learning theory, and institutional theory. The constraints and bottlenecks of moving from traditional measures of performance to SSQI measures of performance can be examined by using the perspectives from structural contingency theory. Potential research propositions are presented below:

P16: The interaction of SSQI measurement system and the strategic intent of a firm is positively associated with performance.

P17: SSQI metrics is positively associated with cross-functional collaboration.

\section{Project selection}

Project selection is an important aspect of SSQI and is a key determinant of SSQI project implementation success, yet it has not received adequate research attention. Popular business press has suggested some project selection criteria. For example, Pande et al. (2000) present the following criteria for selecting a SSQI project: 
I) Results or Business Benefits Criteria:

II) Organizational Impact Criteria

III) Feasibility Criteria

a. Resources needed: How many people, how much time, how much money is this project likely to need?

b. Expertise available: What knowledge or technical skills will be needed for this project? Do we have them available and accessible?

c. Complexity: How complicated or difficult do we anticipate it will be to develop the Improvement solution? To implement it?

d. Likelihood of success: Based on what we know, what is the likelihood that this project will be successful (in a reasonable timeframe)?

e. Support or Buy-in: How much support for this project can we anticipate from key groups within the organization? Will we be able to make a good case for doing this project?

Operationalization of validated constructs representing these project selection criteria presents a promising avenue for future research. The following propositions can be tested in future research:

P18: Project selection is positively associated with attainment of SSQI performance goals.

P19: Project selection is positively associated with project feasibility.

The performance criteria presented in (I) and (II) can be individually examined in the form of propositions by considering the positive association of project selection with customer satisfaction (P18a), competitive advantage (P18b), financial performance (P18c), learning benefits (P18d), and cross-functional collaboration (P18e). Similarly, the various feasibility issues stated in (III) can be individually expressed in the form of propositions by considering: resource availability (P19a), managerial skills (P19b), product complexity (P19c), and organizational support (P19d).

Theoretical investigations regarding cost-benefit analysis of SSQI projects can use expectancy theory and goal setting theory as foundations. The context dependence of project selection can be examined by using structural contingency theory. Finally, organizations need to balance their short-term and long-term goals when selecting SSQI projects. The trade-offs between long-term and short-term goals associated with SSQI projects can be investigated by using structural contingency theory and resource dependence theory.

\section{Project management}

Research studies in SSQI project management need to consider issues of appropriate project team structure. Theoretical perspectives, such as need theories and job design, social context effects and groups, and structural contingency theory provide the basis for future research investigations. Project staffing, role definitions and incentives are other important aspects associated with SSQI project management, which can be examined by using needs theory, operant conditioning, and role theories.

Project management in SSQI relies heavily on managing explicit and tacit knowledge. The knowledge management issues can be examined by using the theoretical lenses of 
social information processing and social learning. Expectancy theory and goal setting perspectives can help in understanding the difference between the DMAIC approach of SSQI and Plan-Do-Check/Study-Act (PDCA/PDSA) approach suggested by Shewhart/ Deming. Researchers can use the perspectives from expectancy theory, goal setting, structural contingency theory, institutional theory and social context effects and groups to operationalize several important constructs in SSQI project management. The following propositions can be examined in future studies:

P20: Process type influences SSQI project team structure

P21: The role of black belts in an organization influences SSQI project team structure.

P22: Project goals influence SSQI project team structure.

P23: The role of external consultant influence SSQI project team structure.

Project management is targeted towards ensuring successful SSQI project implementation. The following propositions relate to the implementation success of SSQI projects:

P24a: Top management commitment is positively associated with the implementation success of SSQI projects.

P24b: Use of measurement systems is positively associated with the implementation success of SSQI projects.

P24c: Internal \& external benchmarking is positively associated with the implementation success of SSQI projects.

P24d: Incorporation of stretch goals is positively associated with the implementation success of SSQI projects.

P24e: Six Sigma training at different organizational levels is positively associated with the implementation success of SSQI projects.

P24f: Verbal and written publicity of the Six Sigma implementation efforts is positively associated with the implementation success of SSQI projects.

\section{Context dependence}

The role of moderating variables is an active area of research investigation in quality management literature (see for example, Powell 1995; Samson and Terziovski 1999; Douglas and Judge 2001; Sousa and Voss 2001). Future research investigating SSQI issues should take the aspect of context dependence into consideration. Structural contingency theory and resource dependence theory provide the foundation for understanding the potential moderating variables and contexts that influence the relationship between SSQI project implementation and performance. We highlighted the role of moderating variables while discussing the integration/distinction issues between SSQI and TQM. The associated propositions and consideration of other potential contextual variables present a promising area for further research investigations in SSQI.

\section{Process design/redesign}

DFSS provides a choice that is mid-way between the incremental quality improvements espoused in TQM and the radical process changes suggested in Business Process Reengineering (BPR). Adoption of the DFSS approach relies on appropriate expectations and goals for quality improvement. The association between the timing of DFSS 
implementation and sigma level need to be verified by further research. Expectancy theory, goal setting, and decision processes and administrative theories provide the theoretical perspectives to investigate Six Sigma process design/redesign issues. We propose:

P25: The implementation of DFSS approach is associated nonlinearly with the sigma level of the process.

\section{Ongoing improvement}

While successfully implementing a SSQI project is important, it is critical to pursue an agenda for ongoing improvement using the SSQI approach. The role of organizational norms in fostering ongoing improvement can be theoretically examined by using institutional theory. Organization structure and the roles and responsibilities of various organizational entities play an important role in ongoing improvement. Needs theory and role theories provide the framework for further investigation. The constraints in pursuing ongoing improvements in a SSQI setting can be examined by using resource dependence and structural contingency theories. Appropriate rewards and motivation protocols are essential to continue ongoing improvement. Operant conditioning provides a framework for future theoretical investigations pertaining to rewards and incentive structure. The ongoing improvement could be aimed at maintaining the quality level, improving the quality level or could be situation dependent. The measures for ongoing improvement from these perspectives can be studied by using expectancy theory, goal setting theory and structural contingency theory. The following propositions are presented:

P26: Institutional norms are positively associated with ongoing SSQI.

P27: Organizational structure is positively associated with ongoing SSQI.

P28: Top management commitment is positively associated with ongoing SSQI.

P29: Reward and incentive structures in an organization are positively associated with ongoing SSQI.

\section{Increasing/diminishing returns}

Anecdotal evidence from SSQI project implementations suggests that firms accrue increasing returns as they move from three sigma quality levels to 4.7 sigma level. Beyond 4.7, the investments aimed towards the six sigma goal yield diminishing returns (Harry and Schroeder 2000). Further studies are needed to understand the theoretical basis underlying this anecdotal evidence. It is important to understand when incremental quality improvement is suitable and when it is appropriate for firms to undertake the DFSS approach. Structural contingency theory and resource dependence perspective can be used to theoretically investigate these issues and gain insights into increasing returns and tradeoffs associated with SSQI implementation. We propose:

P30: Return on investments in SSQI projects follows an S-curve; initially there are increasing returns but as the sigma level goes beyond a certain level firms experience diminishing returns. 
Table 3 Positioning research issues pertaining to SSQI in the organization theory typology

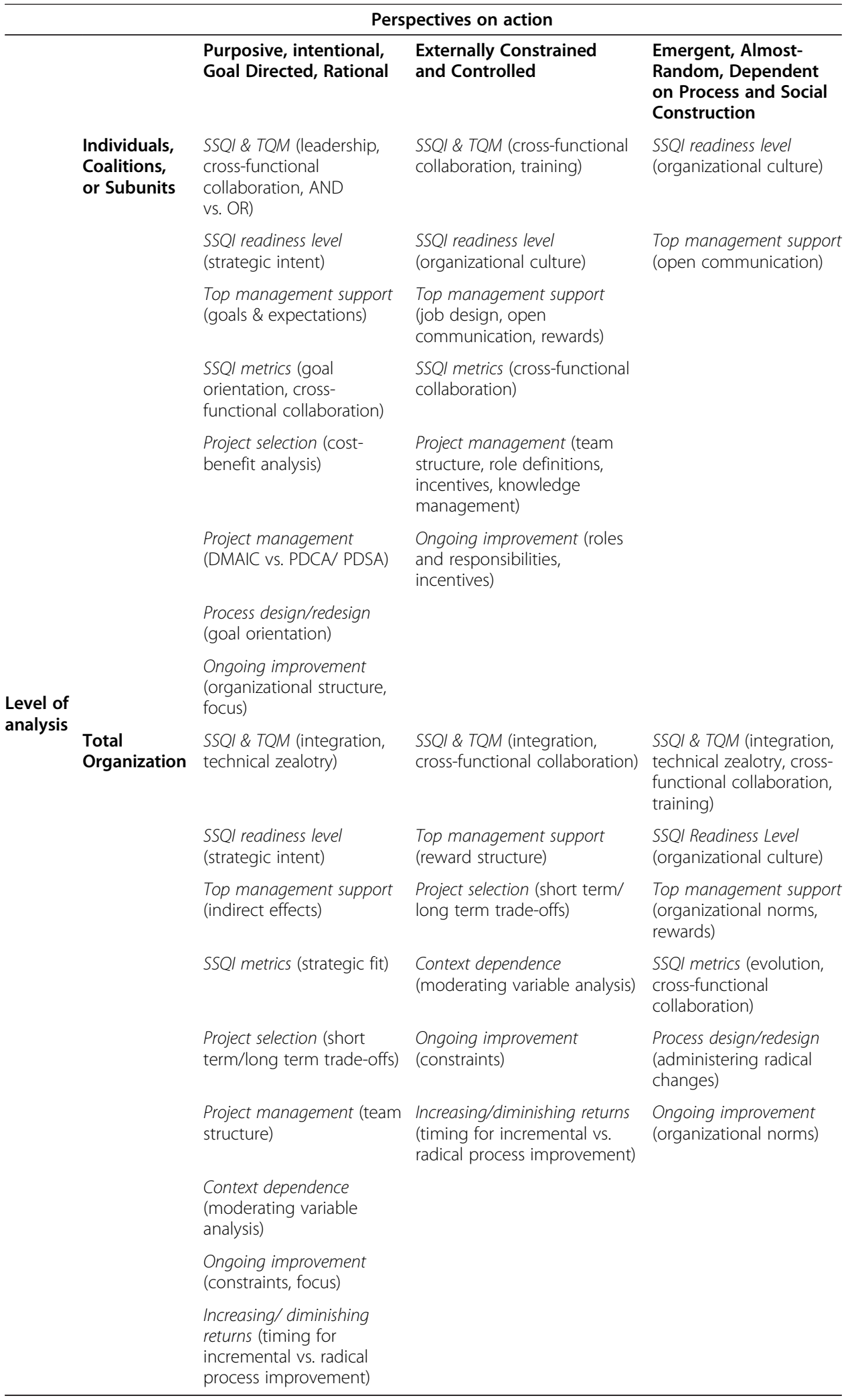


Table 4 Linking Six Sigma research issues with theoretical perspectives

\begin{tabular}{|c|c|c|c|c|c|c|c|c|c|c|c|c|c|c|c|c|c|c|c|c|c|c|c|c|}
\hline & Theories $\rightarrow$ & ET & GS & NT & PT & OC & SL & so & RT & SC & RR & SI & EM & CT & LO & AP & ST & $\mathrm{TC}$ & MC & $\mathrm{PE}$ & RD & OP & DP & IT \\
\hline & Research Issues $\downarrow$ & & & & & & & & & & & & & & & & & & & & & & & \\
\hline \multirow[t]{9}{*}{ SSQI \& TQM } & Integration & & & & & & & & & & & & & & & & $x$ & & & & $x$ & $x$ & $x$ & $x$ \\
\hline & Leadership & $x$ & $x$ & & & & & & & & & & & & & & & & & & & & & \\
\hline & Fuzziness & $x$ & $x$ & & & & & & & & & & & & & & & & & & & & & \\
\hline & Goal-orientation & $x$ & $x$ & & & & & & & & & & & & & & & & & & & & & \\
\hline & Use of tools & & & & & & & & & & & & & & & & & & & & & & & \\
\hline & Cross-functional orientation & & $x$ & $x$ & & & $x$ & & $x$ & $x$ & & $x$ & & & & & $x$ & & & & & $x$ & $x$ & $x$ \\
\hline & "OR" vs. "AND" orientation & $x$ & $x$ & & & & & & & & & & & & & & & & & & & & & \\
\hline & Training & & & & & & $x$ & & & & & $x$ & $x$ & $x$ & & & & & & & & & $x$ & $x$ \\
\hline & Focus & $x$ & $x$ & & & & & & & & & & & & & & & & & & & & & \\
\hline \multirow[t]{2}{*}{ SSQI Readiness Level } & Strategic intent & $x$ & $x$ & & & & & & & & & & & & & & & & & & & & & \\
\hline & Relationship with implementation success & & & & & & & & & & & & & $x$ & & & $x$ & & & & & & & \\
\hline \multirow{2}{*}{$\begin{array}{l}\text { Top Management } \\
\text { Support }\end{array}$} & Role of top management & $x$ & $x$ & $x$ & & & & & $x$ & & & & & & & & & & & & & & $x$ & $x$ \\
\hline & Rewards, penalties \& motivation protocols & & & $x$ & & $x$ & & & & & & $x$ & & & & & & & & $x$ & & & $x$ & $x$ \\
\hline \multirow{6}{*}{$\begin{array}{l}\text { Choice of Appropriate } \\
\text { Metrics }\end{array}$} & Integration \& Aggregation & $x$ & $x$ & $x$ & & & & & & & & & & & & & & & & & & & & \\
\hline & Theory development & & & & & & & & & & & & & & & & & & & & & $x$ & $x$ & $x$ \\
\hline & Strategic \& Operational Intent & $x$ & $x$ & & & & & & & & & & & & & & $x$ & & & & & & & \\
\hline & Cross-functional collaboration & $x$ & $x$ & $x$ & & & $x$ & & $x$ & $x$ & & $x$ & & & & & & & & & & & & $x$ \\
\hline & Measure validation \& relatedness & & $x$ & & & & & & & & & & & & & & & $x$ & & & & & & \\
\hline & Constraints \& Bottlenecks & & & & & & & & & & & & & & & & $x$ & & & & & & & \\
\hline \multirow[t]{3}{*}{ Project Selection } & Strategic cost-benefit analysis & $x$ & $x$ & & & & & & & & & & & & & & $x$ & & & & $x$ & & & \\
\hline & Context dependence & & & & & & & & & & & & & & & & $x$ & & & & & & & \\
\hline & Managing trade-offs & & & & & & & & & & & & & & & & & & & & $x$ & & & \\
\hline Project management & Team structure & & & $x$ & & & & & & $x$ & & & & & & & $x$ & & & & & & & \\
\hline
\end{tabular}


Table 4 Linking Six Sigma research issues with theoretical perspectives (Continued)

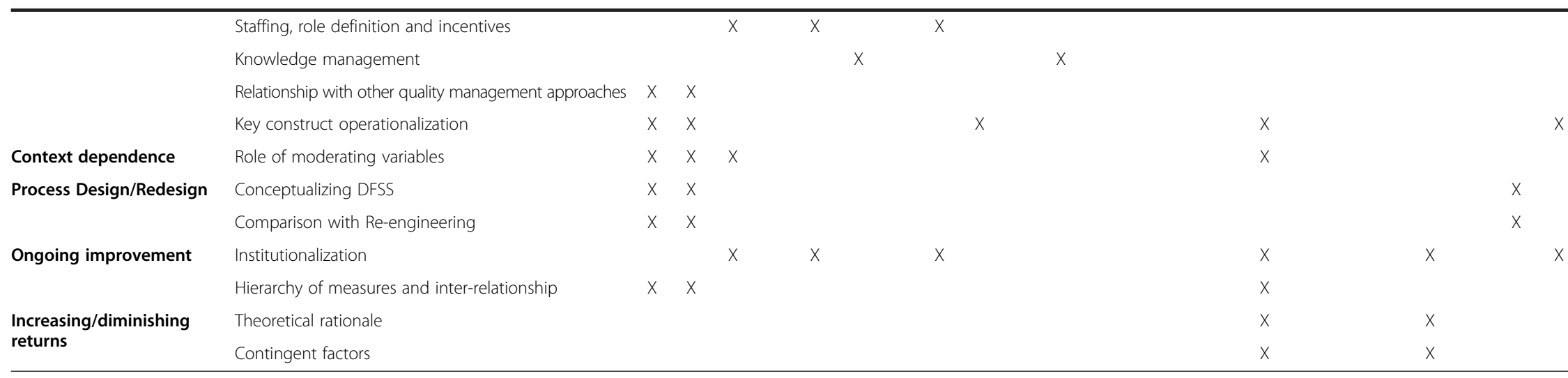

ET: Expectancy theory.

GS: Goal setting.

NT: Needs theories and job design.

PT: Political theories.

OC: Operant conditioning.

SL: Social learning theory.

SO: Socializations.

RT: Role theories.

SC: Social context effects and groups.

RR: Retrospective rationality.

SI: Social information processing

EM: Ethnomethodology

CT: Cognitive theories of organizations.

LO: Language in organizations.

AP: Affect-base processes.

ST: Structural contingency theory.

TC: Market failures/transaction costs.

MC: Marxist or class perspectives.

PE: Population ecology.

RD: Resource dependence.

OP: Organizations as paradigms.

DP: Decision process and administrative theories.

IT: Institutional theory. 
The above discussion is summarized in Tables 3 and 4. In Table 3, we present the research issues pertaining to SSQI within the framework of organization theory typology in Pfeffer (1982).

Table 4 succinctly presents the potential linkages between the ten areas of SSQI discussed in the paper and the various theoretical perspectives.

\section{Conclusions}

SSQI is increasingly gaining prominence in manufacturing and service organizations. Much has been written about the SSQI approach in practitioner oriented publications (e.g. Hoerl 1998; Hammer 2002; Sodhi and Sodhi 2005) and in best-selling books (e.g. Harry and Schroeder 2000; Pande et al. 2000; Pyzdek 2001). Systematic theory-driven research in SSQI is currently lacking in academic literature. This study presents ten key areas for pursuing research investigations in SSQI, proposes some theoretical perspectives and develops potential research propositions. Theory-driven investigations are needed to improve our understanding and to enhance the knowledge base regarding SSQI.

The typology of theoretical perspectives in Pfeffer (1982) provides a useful basis for examining SSQI issues. It provides guidelines regarding whether issues pertaining to the SSQI approach must be examined at the individual, project, departmental or organization level. Moreover, while certain aspects of quality improvement can be explained by using the rational choice and utility maximization perspective, others might need perspectives that are based on external constraints and the notion of emergence. Research questions must dictate the choice of the theoretical perspective. The theoretical perspectives presented in this paper and the potential linkages between the research problems and the theoretical perspectives in Tables 3 and 4 are but one possible alternative. Certainly, multiple theoretical perspectives can be used to glean insights. It is important to continue the search for suitable theoretical perspectives and refine and augment knowledge about the underlying problem. Quoting Karl Popper:

Whenever a theory appears to you as the only possible one, take this as a sign that you have neither understood the theory nor the problem which it was intended to solve.

- Karl Popper

\section{Endnote}

"We use the term "Six Sigma quality innovation" to refer to the quality based innovation utilizing the Six Sigma approach.

Competing interests

The authors declare that they have no competing interests.

Authors' contributions

RN and AN participated in writing and conceptual development of the article. All authors read and approved the final manuscript.

Author details

${ }^{1}$ College of Business, Michigan State University, East Lansing, MI 48824, USA. ${ }^{2}$ Department of Supply Chain

Management, College of Business, Michigan State University, East Lansing, MI 48824, USA. 


\section{References}

Adam EE Jr, Corbett LM, Flores BE, Harrison NJ, Lee TS, Rho BH, Ribera J, Samson D, Westbrook R (1997) An international study of quality improvement approach and firm performance. International Journal of Operations and Production Management 17:842-873

Ahire SL, Golhar DY, Waller MA (1996) Development and validation of TQM implementation constructs. Decis Sci 27:23-56

Ahire SL, O'Shaughnessy KC (1998) The role of top management commitment in quality management: an empirical analysis of the auto parts industry. Int J Qual Sci 3(1):5-37

Alderfer CP (1972) Human needs in organizational settings. Free Press of Glencoe, New York, NY

Aldrich HE, Pfeffer J (1976) Environments of organizations. In: Inkeles A, Coleman J, Smelser N (eds) Annual Review of Sociology, vol 2. Annual Reviews, Palo Alto, CA, pp 79-105

Anderson JC, Rungtusanatham M, Schroeder RG, Devaraj S (1995) A path analytic model of a theory of quality management underlying the Deming Management Method: preliminary empirical findings. Decis Sci 26:637-658 Aronson E (1972) The Social Animal. W. H. Freeman, San Francisco, CA

Bandura A (1977) Social learning theory. Prentice-Hall, Englewood Cliffs, NJ

Benson G, Saraph J, Schroeder R (1991) The effects of organizational context on quality management: an empirical investigation. Manag Sci 37(9):1107-1124

Blalock HM Jr (1967) Status inconsistency, social mobility, status integration and structural effects. Am Sociol Rev 32:790-801

Blau PM (1960) Structural effects. Am Sociol Rev 25:178-193

Brown RH (1978) Bureaucracy as Praxis: Toward a Political Phenomenology of Formal Organizations. Adm Sci Q 23:365-382

Collins R (1981) On a microfoundations of macrosociology. Am J Sociol 86:984-1014

Daft RL, Lengel RH (1986) Organizational information requirements, media richness, and structural design. Manag Sci 32:554-571

Daft RL, Sormunen J, Parks D (1988) Chief executive scanning, environmental characteristics, and company performance: An empirical study. Strateg Manag J 9:129-139

Douglas TJ, Judge WQ Jr (2001) Total quality management implementation and competitive advantage: the role of structural control and exploration. Acad Manage J 44:158-169

Easton GS, Rosenzweig ED (2012) The role of experience in six sigma project success: An empirical analysis of improvement projects. J Oper Manag 30(7):481-493

Flynn BB, Schroeder RG, Sakakibara S (1995) The impact of quality management practices on performance and competitive advantage. Decis Sci 26:659-691

Galbraith JR (1973) Designing Complex Organizations. Addison-Wesley, Reading, MA

Gephart RP Jr (1978) Status degradation and organization succession: An ethnomethodological approach. Adm Sci Q 23:553-581

Goodman PS (1968) The measurement of an individual's organization map. Adm Sci Q 13:246-265

Hammer M (2002) Process Management and the Future of Six Sigma. MIT Sloan Manag Rev 43(2):26-32

Hannan MT, Freeman J (1977) The population ecology of organizations. Am J Sociol 82:929-964

Harry MJ, Schroeder RR (2000) Six sigma: the breakthrough management strategy revolutionizing the world's top corporations. Currency Publications, New York

Heydebrand W (1977) Organizational contradictions in public bureaucracies: Towards a Marxian theory of organization. Sociological Quarterly 18:83-107

Hoerl RW (1998) Six Sigma and the Future of the Quality Profession. Quality Progress 31:35-42

Juran JM, Gryna FM (1988) Juran's Quality Control Handbook, 4th edn. McGraw-Hill, New York

Juran JM, Gryna FM (1993) Quality Planning and Analysis, 3rd edition. McGraw-Hill, New York

Kahn RL, Wolfe DM, Quinn RP, Snoek JD (1964) Organization Stress: Studies in Role Conflict and Ambiguity. John Wiley, New York, NY

Kaynak H (2003) The relationship between total quality management practices and their effects on firm performance. J Oper Manag 21:405-435

Kekre S, Murthi B, Srinivasan K (1995) Operating decisions, supplier availability and quality: an empirical study. J Oper Manag 12:387-396

Linderman K, Schroeder RG, Zaheer S, Choo AS (2003) Six Sigma: A goal-theoretic perspective. J Oper Manag 21(2):193-203

Locke EA (1968) Towards a theory of task motivation and incentives. Organ Behav Hum Perform 3:157-189

Lord RG, Maher KJ (1990) Alternative information-processing models and their implications for theory, research, and practice. Acad Manage Rev 15:9-28

Maani K (1989) Productivity and profitability through quality - myth and reality. International Journal of Quality and Reliability Management 11(7):19-37

Madu C, Kuei C, Lin C (1995) A comparative analysis of quality practice in manufacturing firms in the US and Taiwan. Decis Sci 26(5):621-636

March JG, Olsen HA (1976) Ambiguity and Choice in Organizations. Universitetsforlaget, Bergen, Norway

Maslow AH (1943) A theory of human motivation. Psychol Rev 50:370-396

McAdam R, Lafferty B (2004) A multilevel case study critique of Six Sigma: Statistical Control or Strategic Change? International Journal of Operations and Production Management 24(5):530-549

Melnyk SA, Stewart DM, Swink M (2004) Metrics and performance measurement in operations management: dealing with the metrics maze. J Oper Manag 22:209-217

Meyer JW, Rowan B (1977) Institutionalized organizations: Formal structure as myth and ceremony. Am J Sociol 83:340-363

Nair A, Malhotra MK, Ahire SL (2011) Toward a theory of managing context in Six Sigma process-improvement projects: An action research investigation. J Oper Manag 29(5):529-548

Pande PS, Neuman RB, Cavanagh RR (2000) The Six Sigma Way: How GE, Motorala, and Other Top Companies are Honing Their Performance. McGraw Hill, New York

Pfeffer J (1981) Power in Organizations. Pitman Publishing Inc., Marshfield, MA

Pfeffer J (1982) Organizations and Organization Theory. Pitman Publishing Inc., Marshfield, MA 
Pfeffer J, Salancik GR (1978) The external control of organizations: A resource dependence perspective. Harper \& Row, New York, NY

Pondy LR (1978) Leadership in a language game. In: McCall MW Jr, Lombardo MM (eds) Reward systems and power distribution. School of Industrial and Labor Relations, Cornell University, Ithaca, NY, pp 56-91

Powell TC (1995) Total quality management as competitive advantage: a review and empirical study. Strateg Manag J 16:15-37

Pyzdek T (2001) The Six Sigma handbook: a complete guide for greenbelts, blackbelts, and managers at all levels. McGraw-Hill, New York

Rose K (1995) A performance measurement model. Qual Prog 28(2):63-66

Salancik GR, Pfeffer J (1978) A social information processing approach to job attitudes and task design. Adm Sci Q 23:224-253

Samson D, Terziovski M (1999) The relationship between total quality management practices and operational performance. J Oper Manag 17:393-409

Skinner BF (1953) Science and Human Behavior. Macmillan, New York, NY

Sodhi MS, Sodhi NS (2005) Six Sigma Pricing. Harv Bus Rev 83(5):135-142

Sousa R, Voss CA (2001) Quality management: Universal or context dependent. Prod Oper Manag 10(4):383-404

Swink M, Jacobs BW (2012) Six Sigma adoption: operating performance impacts and contextual drivers of success. J Oper Manag 30(6):437-453

Van Maanen J (1976) Breaking In: Socialization to Work. In: Dubin R (ed) Handbook of Work, Organization, and Society. Rand McNally, Chicago, IL, pp 67-130

Vroom VH (1964) Work and Motivation. John Wiley, New York, NY

Williamson OE (1975) Markets and Hierarchies: Analysis and Antitrust Implications. Free Press, New York, NY

Wilson DD, Collier DA (2000) An empirical investigation of the Malcolm Baldrige National Quality award causal model. Decis Sci 31:361-390

Zu X, Fredendall LD, Douglas TJ (2008) The evolving theory of quality management: the role of Six Sigma. J Oper Manag 26(5):630-650

doi:10.1186/s40887-015-0005-7

Cite this article as: Narasimhan and Nair: Towards a theory-driven research agenda in six sigma quality

innovation: linking research opportunities with organization theory typology. International Journal of Quality Innovation 2015 1:5.

\section{Submit your manuscript to a SpringerOpen ${ }^{\circ}$ journal and benefit from:}

- Convenient online submission

- Rigorous peer review

- Immediate publication on acceptance

- Open access: articles freely available online

- High visibility within the field

- Retaining the copyright to your article

Submit your next manuscript at $\gg$ springeropen.com 